\title{
Enhancement of Heat Transfer with Pool and Spray Impingement Boiling on Microporous and Nanowire Surface Coatings
}

Conference Paper NREL/CP-540-48055

August 2010

S.J. Thiagarajan, W. Wang, and R. Yang University of Colorado

S. Narumanchi and C. King National Renewable Energy Laboratory

Presented at the $14^{\text {th }}$ International Heat Transfer Conference (IHTC-14)

Washington, DC

August 8-13, 2010 


\section{NOTICE}

The submitted manuscript has been offered by an employee of the Alliance for Sustainable Energy, LLC (Alliance), a contractor of the US Government under Contract No. DE-AC36-08GO28308. Accordingly, the US Government and Alliance retain a nonexclusive royalty-free license to publish or reproduce the published form of this contribution, or allow others to do so, for US Government purposes.

This report was prepared as an account of work sponsored by an agency of the United States government. Neither the United States government nor any agency thereof, nor any of their employees, makes any warranty, express or implied, or assumes any legal liability or responsibility for the accuracy, completeness, or usefulness of any information, apparatus, product, or process disclosed, or represents that its use would not infringe privately owned rights. Reference herein to any specific commercial product, process, or service by trade name, trademark, manufacturer, or otherwise does not necessarily constitute or imply its endorsement, recommendation, or favoring by the United States government or any agency thereof. The views and opinions of authors expressed herein do not necessarily state or reflect those of the United States government or any agency thereof.

Available electronically at http://www.osti.gov/bridge

Available for a processing fee to U.S. Department of Energy and its contractors, in paper, from:

U.S. Department of Energy

Office of Scientific and Technical Information

P.O. Box 62

Oak Ridge, TN 37831-0062

phone: 865.576 .8401

fax: 865.576.5728

email: mailto:reports@adonis.osti.gov

Available for sale to the public, in paper, from:

U.S. Department of Commerce

National Technical Information Service

5285 Port Royal Road

Springfield, VA 22161

phone: 800.553.6847

fax: 703.605.6900

email: orders@ntis.fedworld.gov

online ordering: http://www.ntis.gov/ordering.htm 


\section{ENHANCEMENT OF HEAT TRANSFER WITH POOL AND SPRAY IMPINGEMENT BOILING ON MICROPOROUS AND NANOWIRE SURFACE COATINGS}

\author{
Suraj Joottu Thiagarajan \\ Department of Mechanical Engineering \\ University of Colorado \\ Boulder, Colorado, USA
}

\author{
Sreekant Narumanchi ${ }^{\dagger}$ and Charles $\mathrm{King}^{\dagger}$ \\ National Renewable Energy Laboratory \\ Golden, Colorado, USA \\ *sreekant.narumanchi@nrel.gov \\ 303-275-4062
}

\author{
Wei Wang and Ronggui Yang \\ University of Colorado \\ Department of Mechanical Engineering \\ Boulder, Colorado, USA
}

\section{ABSTRACT}

The National Renewable Energy Laboratory (NREL) is leading a national effort to develop next-generation cooling technologies for hybrid vehicle electronics, as part of the Advanced Power Electronics and Electrical Machines program area in the U.S. Department of Energy's (DOE's) Vehicle Technologies Program. The overarching goal is to reduce the size, weight, and cost of power electronic modules that convert direct current from the batteries to alternating current for the motor, and vice versa. Aggressive thermal management techniques help in achieving the goals of increased power density and reduced weight and volume, while keeping the chip temperatures within acceptable limits. The viability of aggressive cooling schemes such as spray and jet impingement in conjunction with enhanced surfaces is being explored as part of the program. In this work, we present results from a series of experiments with pool and spray boiling on enhanced surfaces, such as a microporous layer of copper and copper nanowires, using HFE-7100 as the working fluid. Spray impingement on the microporous coated surface showed an enhancement of $100 \%-300 \%$ in the heat transfer coefficient at a given wall superheat with respect to spray impingement on a plain surface under similar operating conditions. The critical heat flux also increased by $7 \%-20 \%$, depending on the flow rates. Heat transfer coefficients obtained on the nanowire-grown surface are considerably better than those obtained on the plain surface, although the enhancement is lower than those obtained on the microporous surface. The critical heat flux is also considerably lower for the nanowire surface than for the plain surface.

${ }^{\dagger}$ Employees of the Alliance for Sustainable Energy, LLC (ASE), a contractor of the U.S. Government under Contract No. DE-AC36-08GO28308. The U.S. Govt. and ASE retain a nonexclusive royalty-free license to publish or reproduce this contribution, or allow others to do so, for U.S. Govt. purposes.

\section{KEY WORDS}

Electronics cooling, pool boiling, spray cooling, surface enhancements, microporous surface, nanowire, HFE-7100

\section{INTRODUCTION}

The unprecedented increase in interest in the development of a new electric propulsion system to enable the transition from conventional engines to economical hybrid vehicles and fully electric vehicles in the last few years has led to a major collaborative effort through the DOE FreedomCAR and Fuel Partnership [1]. The goal in developing new electric propulsion systems is to decrease their cost to a level that renders hybrid and fuel cell vehicles economically justifiable for the consumer. The state-of-the-art cooling system for power electronics modules using liquid heat exchangers adds a significant amount of cost and weight to the modules. To achieve FreedomCAR goals, significant advances must be achieved in the thermal control of both the power electronics and electrical machines. By optimizing existing technologies and extending them to new cooling methods, NREL aims to achieve higher power densities, smaller volumes and weights, and increased reliability for the drivetrain components.

Achieving high heat flux dissipation is dependent on the chip packaging. Direct cooling of the chips using dielectric fluids will eliminate much of the resistances due to packaging. However, the thermophysical properties of dielectric coolants are considerably worse than those of common coolants such as water-ethylene glycol mixtures. Hence, it is necessary to achieve very high convective heat transfer coefficients to reduce the chip-to-fluid resistance below that of the total resistance in an indirectly cooled package to obtain an advantage with direct cooling. Given the inferior 
thermophysical properties of the dielectric coolants, high heat transfer coefficients can be obtained by using phase change in conjunction with aggressive flow configurations such as spray or jet impingement. In addition, even higher heat transfer coefficients can be obtained by engineering the surface to provide the maximum nucleation site density with minimum superheat.

Several studies in the past explored the effect of enhanced surfaces on pool boiling. A summary of the different surface enhancements and their effect on pool boiling performance is provided in reference [2], in which several forms of microstructure enhancement are reviewed, including laser drilled cavities, reentrant cavities, micro-fins, porous coatings and sputtered surfaces. It has been found that, in general, micro-fins are more effective at increasing the critical heat flux (CHF), while microporous structures are more effective at increasing nucleate boiling heat transfer. Chang and You performed pool boiling experiments [3] with FC-72 on an optimized microporous organic coating made with thermally conductive particles in an organic binder (a "DOA" coating). Despite the low thermal conductivity $(\sim 0.95 \mathrm{~W} / \mathrm{mK})$, these coatings led to a significantly lower nucleate boiling incipience superheat of $<10 \mathrm{~K}$, in comparison to $\sim 30 \mathrm{~K}$ for the plain surface, and resulted in a significant increase in the heat transfer coefficient and critical heat flux. Kim et al. [4] studied the mechanism of pool boiling with FC-72 on cylindrical platinum wire using the consecutive-photo method [5]. They determined the differences (between the microporous coated surface and plain surface) in the latent heat contribution and the bubble size and frequency of departure. They found that the microporous coating enhances the boiling heat transfer by increasing the nucleation site density, and not by increasing the surface area. El-Genk and Parker [6] performed pool boiling tests on commercially available porous graphite with HFE7100. They observed the onset of nucleate boiling in the porous surface at a surface superheat of only $0.5-0.8 \mathrm{~K}$. For comparison, onset occurred on plain copper at a superheat of $\sim 40 \mathrm{~K}$. This resulted in a large increase $(1600 \%$ at $10 \mathrm{~K}$ superheat, and $60 \%$ near $\mathrm{CHF}$ ) in the heat transfer coefficient. The CHF also increased by $60 \%$. They attributed the performance enhancement on the porous graphite layer to the presence of trapped air in the surface pores and re-entrant cavities that form nucleation sites at very small superheat temperatures.

Porous coated surfaces lead to boiling enhancement as a result of a combination of the following factors: an increase in the effective surface area, an increase in the nucleation site density, the presence of capillaries that facilitate liquid flow, and the dependence of the vapor escape path on the pore distribution in the layer adjacent to the liquid. The interconnected pore assists the flow of fluid toward the heated surface by capillary action. By proper design of the porous layer, the CHF could also be enhanced by the capillary-assisted liquid flow toward the phase-change interface. This reduces liquid vapor counter flow resistance and impedes the development of localized dry-out conditions leading to a higher CHF [7].

More recently, copper and silicon nanowires grown on the heater surfaces under pool boiling with water have been shown to enhance the nucleation site density at a given superheat and bubble release frequency [8] and to increase both the heat transfer and CHF [9]. Contrary to the traditional belief that nanoscale structures will not enhance nucleate boiling heat transfer because the size scale is too small to induce bubble nucleation, these works have shown enhanced performance [8]. This is attributed to the increased wetting of the surface due to the presence of the nanowires and to micron-sized defects or voids formed between the nanowires, which form favorable sites for bubble nucleation. However, in the case of highly wetting dielectric fluids like HFE-7100, the effect of wetting enhancement due to the nanowires may be small, and the presence of the voids of the optimum shape and size may be the more important factor in the boiling enhancement.

The use of enhanced surfaces on spray cooling has received much less attention in comparison to their application to pool boiling. Comparison of spray cooling with other phasechange cooling techniques such as pool boiling and microchannel cooling and jet impingement $[10,11]$ shows that significantly higher quantities of heat can be removed at a low superheat with spray cooling. A uniform dispersal of the liquid droplets impinging on the heater surface in a spray gives rise to a more uniform spatial surface temperature distribution over the entire spray impact area. Further, boiling incipient superheat, which may cause a severe thermal shock to electronic components and make the heat transfer performance highly unpredictable, is much less pronounced in spray cooling systems than in pool or flow boiling systems. Spray cooling can also provide significantly higher $\mathrm{CHF}$ at low values of subcooling in comparison to jet cooling [10]. A review of the spray cooling phenomena as of 2007 is provided in reference [12]. Horacek et al. [13] found that heat flux dissipated from a spray-cooled surface can be correlated to the three-phase contact line length density, and not to the total wetted area. The CHF was reached at the highest contact line density. Kim et al. [14] investigated evaporative spray cooling on a microporous coated surface using water at very low flow rates up to 0.025 $\mathrm{cm}^{3} / \mathrm{cm}^{2} / \mathrm{s}$. The low thermal conductivity (estimated to be $\sim 0.95$ $\mathrm{W} / \mathrm{mK}$ ) porous layer was fabricated using a mixture of methylethylketone, epoxy, and aluminum powder, and its maximum thickness was $500 \mu \mathrm{m}$. They found that the CHF increased by $50 \%$ relative to the uncoated surface. Bostanci et al. [15] performed spray cooling experiments with ammonia on microstructured surfaces with indentations and protrusions with heat fluxes up to $500 \mathrm{~W} / \mathrm{cm}^{2}$. They observed an enhancement of $49 \%-112 \%$ in the heat transfer coefficient with respect to a smooth surface. The increase is believed to be due to the increased surface area, availability of a range of the cavity sizes, and increased contact line length density over the heater surface.

Because of the desirable properties of the fluid HFE-7100 (such as low global warming potential, low ozone depletion 
potential, and high dielectric strength, in addition to good thermophysical properties), it has been identified as a potential coolant for the cooling of power electronic modules in automobiles. However, little research has been carried out with HFE-7100 with aggressive cooling schemes such as sprays and jets. In particular, there exists no study in the literature on the performance of HFE-7100 coolant with spray impingement, in conjunction with enhanced surfaces. The main objective of the present study is to investigate the performance enhancement that can be obtained by novel surface coatings on copper, under pool boiling and spray impingement configurations with the HFE-7100 coolant. Two types of surface coatings were tested: microporous copper coating and electrolytically grown copper nanowire array. The effect of the spray flow rate and liquid subcooling were also studied. In the following sections, the experimental setup and procedure and target surface enhancements are described, followed by a discussion of the results.

\section{EXPERIMENTS}

\section{Setup}

Figure 1 shows the construction of the test heater that is used to simulate the chip. The test heater is a single cylindrical block of oxygen-free copper with a cubical projection whose top face, which has a surface area of $1 \mathrm{~cm} \mathrm{x} 1 \mathrm{~cm}$, is exposed to the coolant. The cubical projection from the cylindrical block is surrounded by an insulating fiberglass (G7) block, which is fabricated to fit tightly along the sides of the cube. Three cartridge heaters, together capable of delivering over $200 \mathrm{~W}$, are placed in holes that are bored in the back of the copper block. The entire heater assembly is mounted on a stainless steel flange, which is then clamped to the chamber. Two type $\mathrm{K}$ thermocouple probes are inserted into the copper block, at a distance of $1.25 \mathrm{~mm}$ and $7.25 \mathrm{~mm}$ from the test surface. The heat flux through the surface $\left(=q_{\text {calc }}\right)$ is determined by the temperature gradient across the two thermocouples. This information is also used to determine the surface temperature (assuming one-dimensional heat flow), and hence the surface heat transfer coefficient. Dow Corning TC-5022 thermal grease is used to provide good thermal contact between the thermocouples/heaters and the copper block.

Heat loss is estimated to range from $6 \%$ to $15 \%$ for a variety of heat transfer coefficients $(h)$ and input power levels $\left(q_{\text {in }}\right)$ in the nucleate boiling regime. The highest losses occur with the lowest $h$ and the lowest $q_{\text {in. }}$. Higher losses (up to 50\%) occur in the single-phase regime in the pool boiling configuration. To ensure that the temperatures read by the thermocouples are the true values (so that the heat flux could be reliably measured by the gradient), steady-state thermal analysis was performed with a 3D ANSYS Workbench model. The analysis was performed at different surface heat fluxes, assuming a uniform heat transfer coefficient at the target surface and a set of heat transfer coefficients for the different modes of heat loss. The set of the coefficients for heat loss used in the analysis was arrived at by iteratively trying different values until temperatures obtained in the ANSYS model (and heat flux from the surface) match the corresponding experimental values.

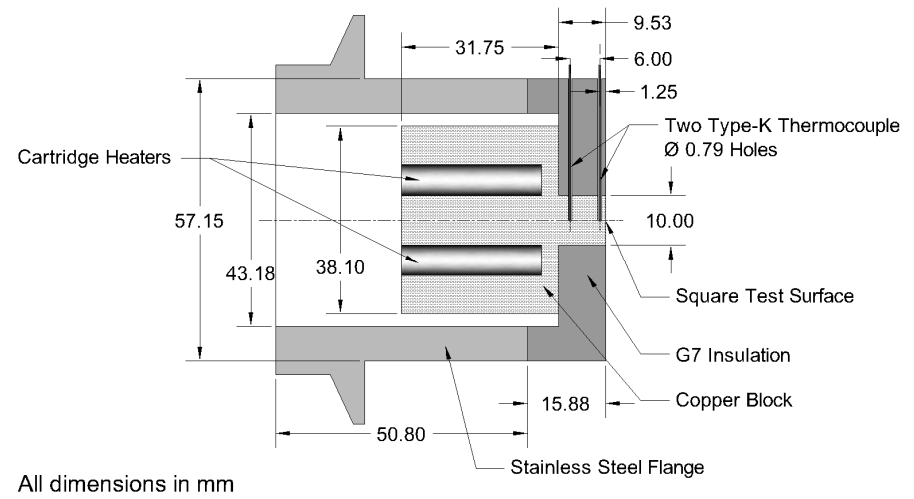

(a)

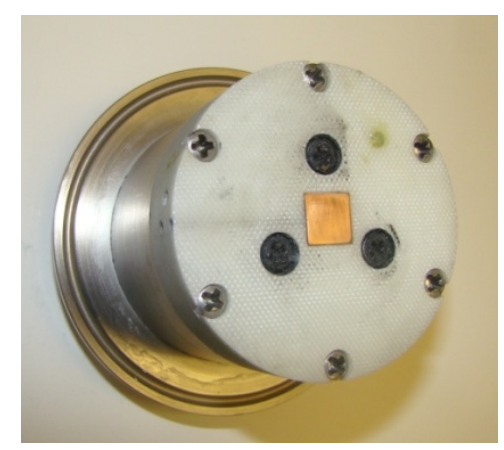

(b)

Figure 1 (a) Construction of test heater assembly, and (b) photo of the assembly, showing the square target surface that is exposed to the coolant (photo by S. Thiagarajan, co-author).

In the model, the input values were the power input $\left(q_{\text {in }}=\right.$ $V I$ through the cartridge heaters) and the loss heat transfer coefficients. The heat loss through the different surfaces (including the target surface) and the temperature at different points within the copper block were the outputs. Figure 2 shows the results for an input heat flux of $100 \mathrm{~W} / \mathrm{cm}^{2}$ with $\mathrm{h}=2.06$ $\mathrm{W} / \mathrm{cm}^{2} \mathrm{~K}$ on the target surface. The temperature in the planes where the thermocouples are placed in the copper block is shown. The temperature is uniform within $0.15^{\circ} \mathrm{C}$ in the plane closer to the surface, and within $0.5^{\circ} \mathrm{C}$ in the plane farther from the surface. This confirms that the surface temperature in the experiments could be taken as the extrapolation of the two thermocouples.

The schematic of the experimental test loop is shown in Fig. 3. It is designed to deliver the test fluid at the desired pressure, temperature, and flow rate to the spray nozzle located inside the test chamber. The coolant is partially evaporated upon impact with the test heater. The remaining liquid accumulates in the bottom of the test vessel, while the vapor is separated from it by buoyancy into the vessel's top region. The liquid from the test vessel drains directly to a pump and then passes through a valve 
and subsequently through a plate-type heat exchanger, where the fluid is subcooled to the required temperature. The subcooled liquid then passes through the flow meter and then through a filter before reaching the spray nozzle. The temperature of the incoming fluid is read by a type $\mathrm{K}$ thermocouple approximately $2.5 \mathrm{~cm}$ from the nozzle exit. The pressure ahead of the nozzle entrance and inside the chamber is measured using pressure transducers. The spray nozzle is a Unijet full cone pressure nozzle, with an orifice diameter of 1.7 $\mathrm{mm}$ and spray angle of $48.5^{\circ}$, made by Spraying Systems Inc. (a)

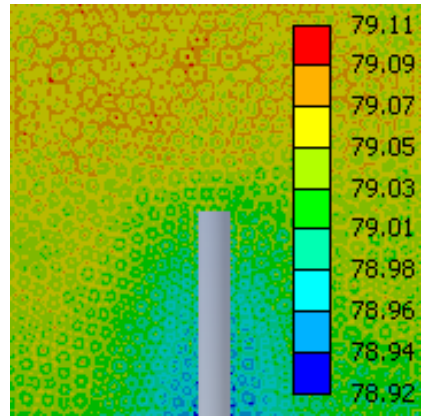

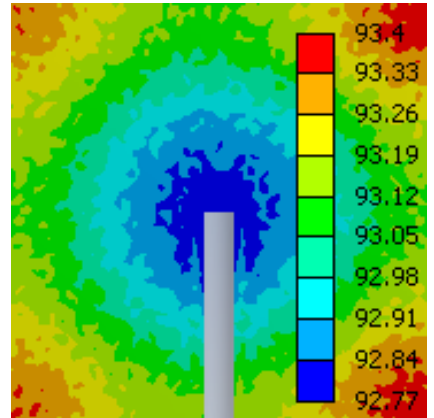

(b)
Figure 2 Temperature $\left({ }^{\circ} \mathrm{C}\right)$ in the plane of each target thermocouple: (a) closer to the surface; (b) farther from the surface.

A separate air-cooled finned-tube heat exchanger is placed above the test vessel for the removal of noncondensable gases from the liquid before each experiment. The test vessel temperature is maintained at a fixed point, within $0.5^{\circ} \mathrm{C}$, using band heaters that heat the liquid through the wall of the vessel. The spray nozzle exit in all experiments is located at a distance of $11.1 \mathrm{~mm}$, so that the square surface is just covered by the spray for maximizing the CHF [16]. The same setup (Fig. 3) is also used for pool boiling. For this purpose, the liquid is filled until it completely submerges the target surface. Note that the heater surface is vertical to the ground in the pool boiling experiments. The input from the different sensors feed in to a data acquisition system and are read using LabVIEW. All the controls are manually operated.

\section{Uncertainties}

The flow meter was calibrated by measuring the total liquid flowing through the circuit in a given time. The uncertainty in the flow rate is estimated to be $\pm 0.17 \mathrm{~cm}^{3} / \mathrm{s}$ in the range of 1.25 to $17 \mathrm{~cm}^{3} / \mathrm{s}$. The pressure transducers were calibrated to an accuracy of $\pm 350 \mathrm{~Pa}$ using a Fluke pressure calibrator. A Hart Scientific thermal bath was used for the calibration of all the thermocouples. The uncertainty in the temperature measured is within $\pm 0.03^{\circ} \mathrm{C}$. The uncertainties in voltage and current are negligibly small. Because of the uncertainty in the positions of the two target thermocouples (estimated to be $\pm 0.125 \mathrm{~mm}$ from the centerline of the holes), and hence the temperature measurements in the target block, it is estimated that the measured heat flux, based on the gradient in the two thermocouple readings, has an uncertainty of $\pm 6 \%$.

\section{Procedure}

In all the experiments reported in this study, the chamber vapor temperature was maintained at $\sim 61^{\circ} \mathrm{C}$, corresponding to a pressure of 1 atmosphere at sea level $(\sim 101 \mathrm{kPa})$. Before each experiment, the fluid was deaerated for 20-45 minutes to expel any dissolved noncondensable gases using the deaeration condenser, while the pump is on and set at a constant predetermined flow rate. After this procedure, the system is allowed to settle on to a steady state with no input power. All the sensor readings are continuously recorded and monitored through LabVIEW.

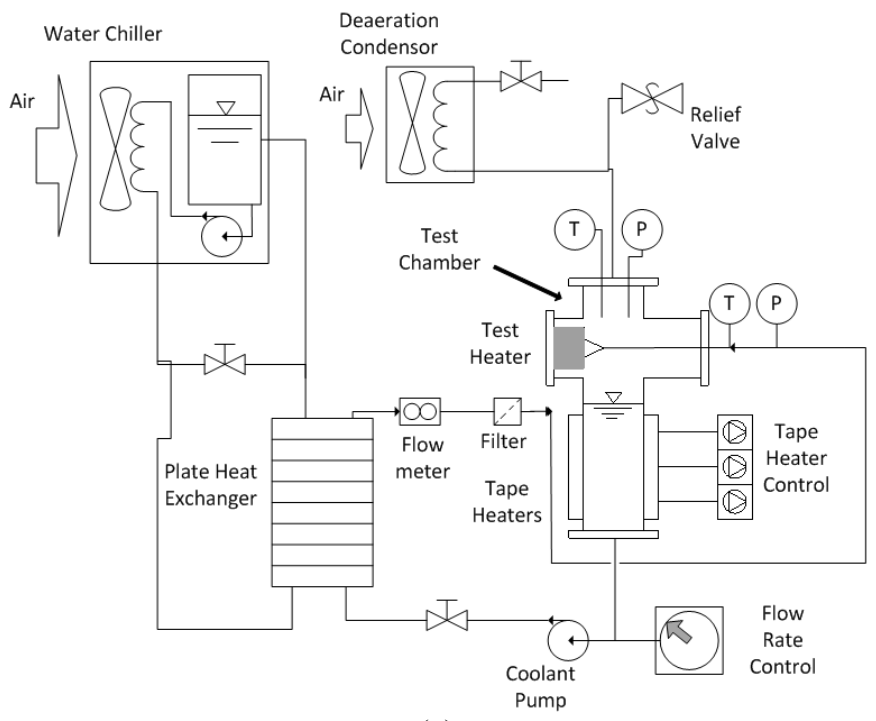

(a)

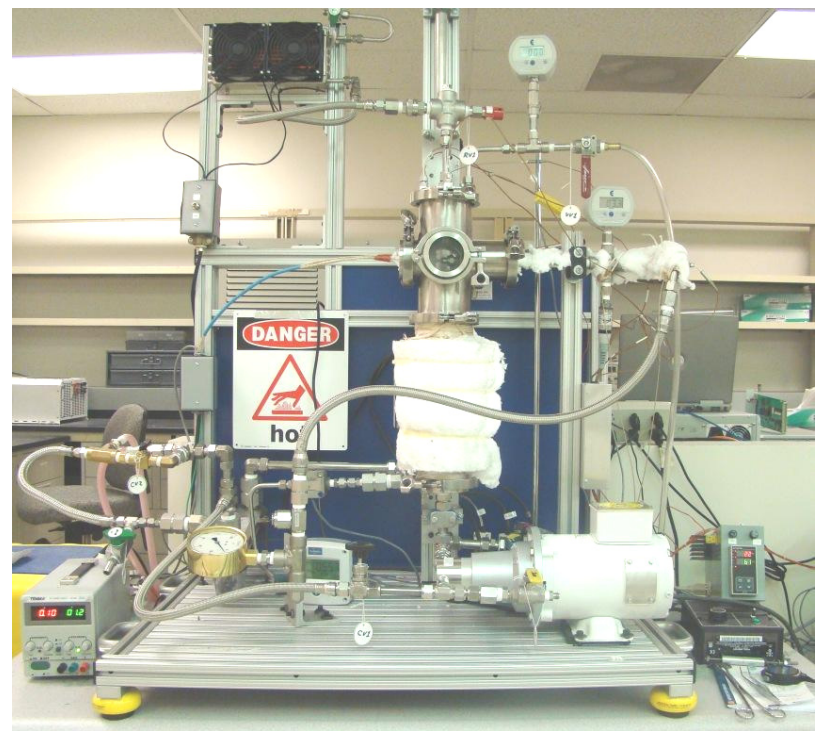

(b)

Figure 3 (a) Schematic of experimental test loop; (b) photo of the test facility (photo by S. Thiagarajan, co-author).

For the spray experiments, two levels of liquid temperatures (in the nozzle) are considered $-31^{\circ} \mathrm{C}$ (subcooling 
$\Delta T_{\text {sub }}=30^{\circ} \mathrm{C}$, henceforth referred to as "subcooled"), and $60^{\circ} \mathrm{C}$ (subcooling $\Delta T_{\mathrm{sub}} \sim 1^{\circ} \mathrm{C}$, henceforth referred to as "nearsaturated"). Boiling curves are generated by raising the voltage through the cartridge heaters in small increments and allowing the temperatures to achieve steady state, which was determined by less than $0.1^{\circ} \mathrm{C}$ change in $5-10$ minutes (depending on the surface). To accurately determine the CHF, the flux increment is kept very small near CHF. The highest heater power with stable target surface temperature is considered to be the CHF, beyond which a sudden, large surge in the temperature measurement occurs with only a small increment in the heat flux. Once the CHF is detected, the heater voltage is cut off and the target is allowed to cool down.

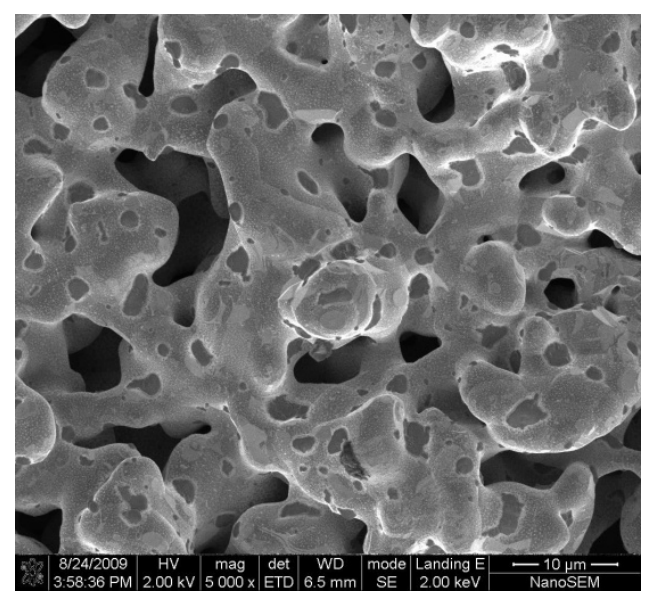

(a)

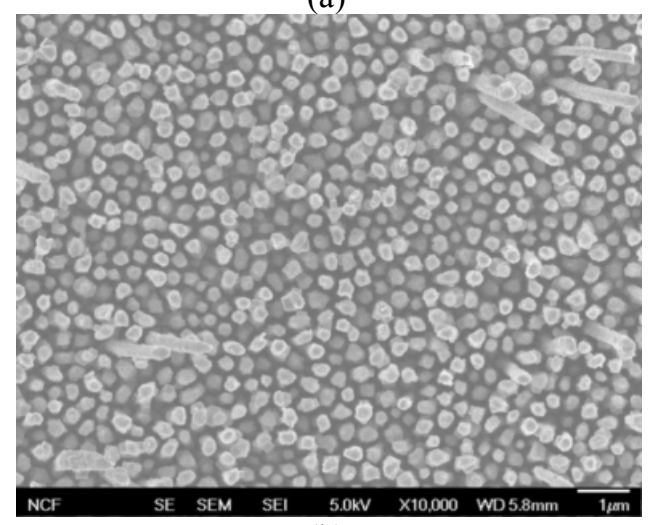

(b)

Figure 4 SEM images showing the microstructure of the (a) microporous coating (image by Bobby To, NREL) and (b) nanowire array (image by Wei Wang, co-author).

\section{Target Surface Enhancements}

Three types of surfaces were studied: the baseline case of a plain copper surface with no coating, a copper microporous coating, and copper nanowire arrays. To ensure reproducible results with the plain copper surface, it was deoxidized before a series of tests with NOXON solution (composition: ammonium hydroxide, limestone, ethanedioic acid, ethanol and isopropanol) and polished using \#600 and \#2000 grit paper in a specific pattern. The surfaces with the enhancements could not be cleaned throughout the experiments because of concerns about damaging the surface.

The target with the copper microporous coating was obtained from 3M Corporation. The procedure for fabricating the microporous layer on the copper target surface involves fusing copper-rich microparticles on the copper surface at a temperature of $\sim 850^{\circ} \mathrm{C}$. The coating is about $150 \mu \mathrm{m}$ thick and is made with copper particles $\leq 20 \mu \mathrm{m}$ in diameter $[17,18]$.

The copper nanowires were grown on the copper surface by means of electrodeposition using a porous anodic alumina as the template. The procedure for the fabrication followed reference [19]. The nanowires have a diameter of 250-300 nm, an interwire gap of $\sim 50-100 \mathrm{~nm}$, and a length of $2 \mu \mathrm{m}$. Figure 4 shows the SEM image of (a) the microporous coating, and (b) the nanowire array (top view).

\section{RESULTS AND DISCUSSIONS}

In the present study, we focused on the determination of the effect of the microporous and nanowire surface structures on the pool/spray boiling performance in comparison to the baseline case of a plain surface. Furthermore, for the microporous coating, we investigated the effect of the liquid flow rate and the subcooling level, but only the effect of the subcooling level for the nanowire sample (in the spray tests). The samples with the coatings are measured in the order of increasing flow rate (after the pool boiling test), so as to minimize the effect of possible surface degradation due to the impact of the high-velocity spray. However, the surface with the nanowire coating showed degraded performance due to the spray even at the lower flow rate. So, spray cooling results for the nanowire surface are provided only for the lowest flow rate.

\section{Pool Boiling Experiments}

The boiling curves for the three surfaces are shown in Fig. 5(a). The heat transfer coefficient, $h=q^{\prime \prime}{ }_{\text {calc }} /\left(T_{w}-T_{\text {liq }}\right)$, calculated with liquid temperature as the reference temperature, at various levels of the heat flux is shown in Fig. 5(b). The onset of nucleate boiling occurs on the microporous surface at a superheat of only $\sim 3^{\circ} \mathrm{C}$ (Fig. 5(a)), in comparison to $\sim 8^{\circ} \mathrm{C}$ in the nanowire surface and $\sim 12^{\circ} \mathrm{C}$ in the plain surface. The microporous surface augmented the heat transfer coefficient by more than $500 \%$, with respect to the plain surface, throughout the nucleate boiling regime at each power level. The CHF is also enhanced by $10 \%$ for the microporous surface with respect to the plain surface. Thus, while there is a considerable enhancement of the $h$, the CHF is only slightly increased. This result is different from that of Rainey and You [20], who obtained almost $60 \%$ enhancement in the CHF with the microporous surface over plain surface using FC-72. Based on the visualization studies performed on platinum wire with microporous coating, Kim et al. (4) explained the enhancement in the CHF as being due to the increase in the microconvection caused by the bubbles. The presence of many active nucleation sites prevents the bubbles from becoming too large before departure and increases the frequency of bubble departure, leading to a better convection heat transfer. It appears that the 
same effect may also be at play in the current experiments, though its effect on CHF seems minimal. The difference in the enhancements of the CHF could also be due to the difference in the properties of the two liquids, in addition to the structure and composition of the microporous layer itself.

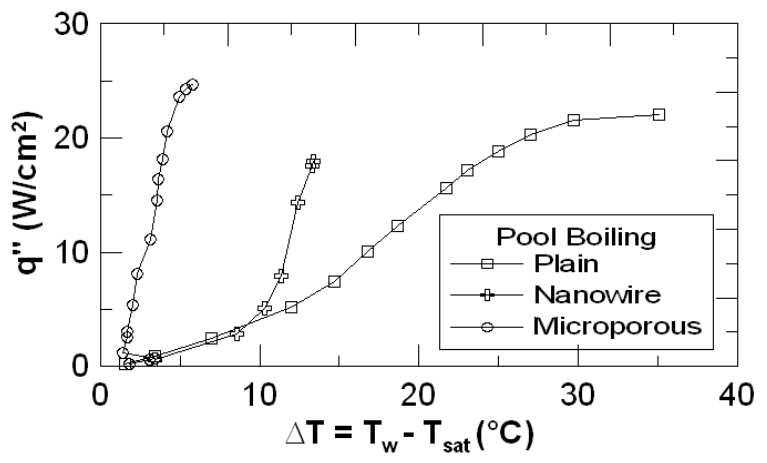

(a)

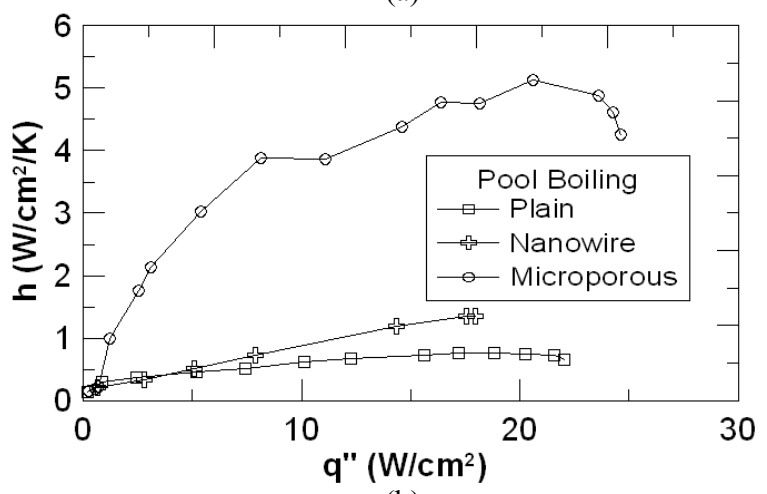

(b)

Figure 5 Plots showing (a) boiling curve and (b) heat transfer coefficient for the pool boiling tests with the three different surfaces, with the surfaces oriented vertically in the pool.

The nanowire surface, while showing an improvement in the $h$ of about $60 \%$ for the same heat flux near CHF, resulted in a lower CHF than the plain surface. Chen et al. [9] studied pool boiling on surfaces with copper nanowire arrays in saturated water. They observed large enhancements $(100 \%)$ in both the $h$ and CHF. The length of the nanowires used in that work was 40-50 $\mu \mathrm{m}$, which is long enough to allow for the agglomeration of the top layer of the nanowires, resulting in the formation of many microscale cavities leading to a higher nucleate site density and hence a higher heat transfer coefficient. Furthermore, they also calculated that the CHF is enhanced as a result of the large capillary action provided by the presence of the nanowires. By reducing the contact angle, the nanowires also increase the surface area wetted by water. The sample used in the current study has nanowires that are only about $2 \mu \mathrm{m}$ long, and hence much too short to agglomerate and form microscale cavities. Moreover, the highly wetting nature of the HFE-7100 could potentially render any additional wetting provided by the nanowires insignificant. Hence, it appears that the presence of the short nanowires does not seem to influence the heat transfer process significantly, while it also reduces the
CHF. Thus, coating with nanowires of optimum length could increase the heat transfer coefficient in the nucleate boiling regime through its effect on the site density, and that is what we are pursuing currently.

In Fig. 5(a), after the onset of nucleation, the slope of the boiling curve for the plain surface is seen to increase at first and decrease as it nears the CHF. This is indicative of the gradual activation of the nucleation sites as the superheat increases. The subsequent drop in the slope is possibly due to the agglomeration and coalescence of the bubbles on the surface leading to local dryouts. In contrast, the boiling curves corresponding to both the microporous surface and the nanowire surface show a sharp increase in the slope, indicating the simultaneous activation of a large number of nucleation sites with the wall temperature/superheat remaining almost constant.

\section{Spray Impingement Experiments}

Experiments with spray impingement were performed on the different surfaces for the combination of parameters shown in Table 1 . The mean velocity shown in the table is simply the ratio of the volumetric flow rate of the liquid to the area of the nozzle orifice $(1.7 \mathrm{~mm}$ in diameter).

Table 1 Matrix of the experiments performed.

\begin{tabular}{|l|r|r|l|}
\hline Surface & \multicolumn{1}{|c|}{$\begin{array}{c}\text { Flow rate } \\
\left(\mathrm{cm}^{3} / \mathrm{s}\right)\end{array}$} & $\begin{array}{c}\text { Mean velocity } \\
(\mathrm{m} / \mathrm{s})\end{array}$ & $\begin{array}{c}\text { Subcooling } \\
\text { level }\end{array}$ \\
\hline \multirow{3}{*}{ Plain } & 4.7 & 2.1 & \\
& 10.2 & 4.5 & $30^{\circ} \mathrm{C}, 1^{\circ} \mathrm{C}$ \\
& 15.8 & 7.0 & \\
Microporous & 4.7 & 2.1 & \\
& 10.2 & 4.5 & $30^{\circ} \mathrm{C}, 1^{\circ} \mathrm{C}$ \\
\hline Nanowire & 15.8 & 7.0 & \\
\hline
\end{tabular}

\section{Effect of liquid subcooling}

Figures 6, 7, and 8 show the boiling curves for the subcooled and near-saturated conditions for the different surfaces at flow rates of $4.7 \mathrm{~cm}^{3} / \mathrm{s}, 10.2 \mathrm{~cm}^{3} / \mathrm{s}$, and $15.8 \mathrm{~cm}^{3} / \mathrm{s}$. In each plot, the solid symbols correspond to the "subcooled" case $\left(T_{\text {nozzle }}=31^{\circ} \mathrm{C}\right)$, and the open symbols correspond to the "near-saturated" case $\left(T_{\text {nozzle }}=60^{\circ} \mathrm{C}\right)$. In the discussion that follows, the heat transfer coefficient is calculated with vapor temperature (chamber $T_{\text {sat }}$ ) as the reference ( $\left.h=q_{\text {calc }} /\left(T_{w}-T_{\text {sat }}\right)\right)$, rather than liquid temperature in the nozzle. In this way, the effect on the heat transfer coefficients of subcooling the liquid is more evident. The heat transfer coefficients corresponding to the data shown in Figs. 6-8 are shown in Fig. 9(b) and Fig. 10(b). In those figures, the $h$ for the single-phase regime is not shown as it is not meaningful, as defined here. 


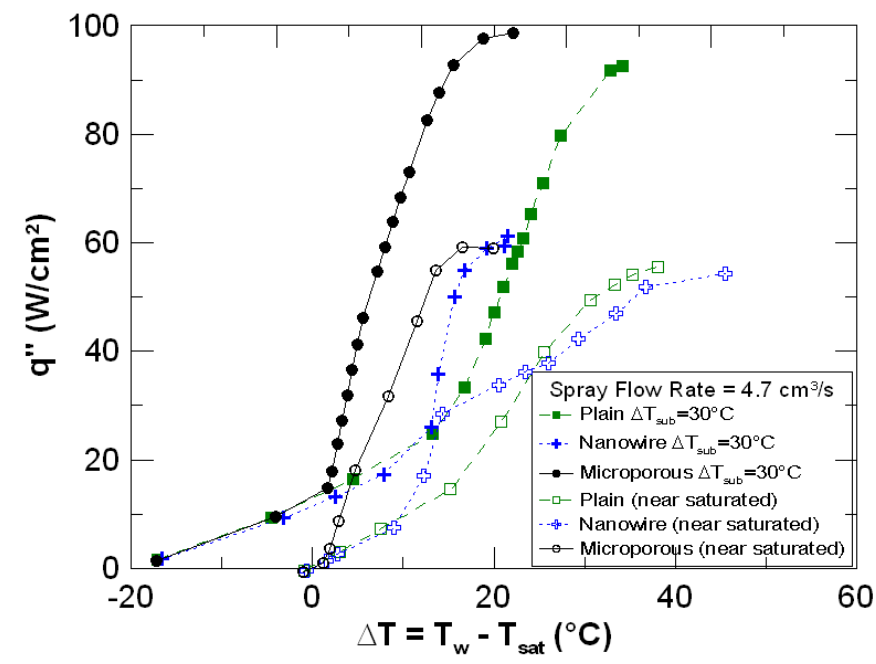

Figure 6 Effect of subcooling on the different surfaces at a spray flow rate $=4.7 \mathrm{~cm}^{3} / \mathrm{s}$.

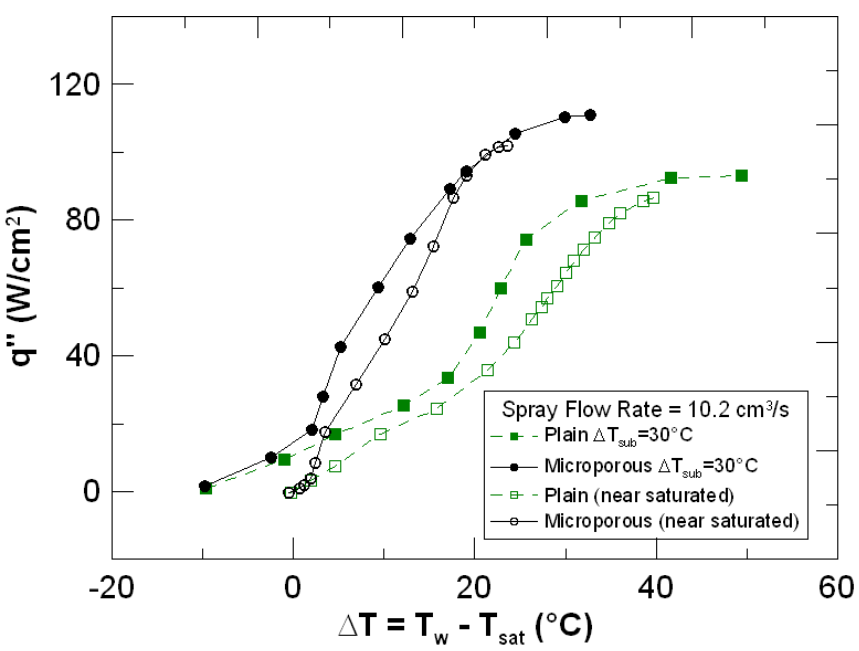

Figure 7 Effect of subcooling on the different surfaces at a spray flow rate $=10.2 \mathrm{~cm}^{3} / \mathrm{s}$.

The enhancement of the $h$ and CHF seen in pool boiling is reproduced with the spray at the low flow rate $\left(4.7 \mathrm{~cm}^{3} / \mathrm{s}\right.$, Fig. 6): the microporous surface shows an increase of $100 \%-300 \%$ in the $h$ in the nucleate boiling regime and $~ 7 \%$ increment in the CHF, while the nanowire surface shows a marginal increase in the $h$ while also showing a considerably lower CHF. Evident from the plots is also the fact that the subcooling of the liquid considerably increases the $h$ and also the CHF in the case of the low flow rate throughout the nucleate boiling regime. While the nanowire surface performs better than the plain surface in the subcooled case, the shape of the boiling curve in the nearsaturated test is possibly indicative of the degradation of the surface, resulting in a performance close to that of the plain surface, including the CHF.

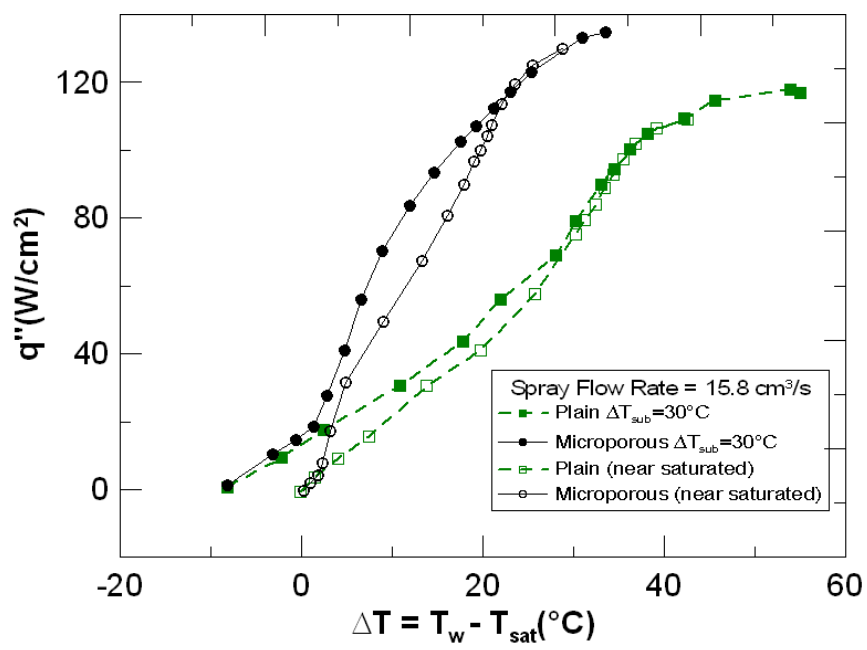

Figure 8 Effect of subcooling on the different surfaces at a spray flow rate $=15.8 \mathrm{~cm}^{3} / \mathrm{s}$.

As expected, the heat transfer coefficient obtained with the subcooled spray is higher than that of the spray with nozzle temperature close to the saturation temperature. This is due to the additional sensible heat removed by the liquid from the surface to heat the liquid up to the saturation temperature. The plots in Figs. 7 and 8 show the performance of the microporous surface, with respect to the plain surface, for the higher flow rates $\left(10.2 \mathrm{~cm}^{3} / \mathrm{s}\right.$ and $\left.15.8 \mathrm{~cm}^{3} / \mathrm{s}\right)$. The large enhancement in the $h$ is seen to continue throughout the range of the flow rate. The CHF also shows a greater enhancement of about $15 \%-20 \%$ for the higher flow rates.

The favorable effect of the liquid subcooling is clearly seen in the lower power levels for both the surfaces (Fig. 6, 7, and 8). However, as the heat flux approaches the CHF, the subcooling has little effect on the $h$ (for the higher flow rates, Figs. 7 and 8), in contrast to the low-flow-rate case (Fig. 6) in which the subcooling is helpful throughout the range. The convergence of the near-saturated and the subcooled curves at the higher heat fluxes shows that the phase-change heat transfer is the dominant heat transfer mechanism. The effect of subcooling is undiminished in the low-flow-rate case (Fig. 6), probably because the CHF occurs before any convergence could be seen, while in the case of the higher flow rates, the CHF is sufficiently delayed for the curves to converge (Fig. 7 and 8). Thus, although the effect of the subcooling is small on the heat transfer coefficient at high heat fluxes for the higher flow rates, it helps in increasing the CHF (very significantly in the case of the spray with the low flow rate, Fig. 6).

\section{Effect of spray flow rate}

Figures 9 and 10 show the boiling curves and heat transfer coefficients for the subcooled spray and the near-saturated spray, respectively. The liquid flow rate has been observed to have a relatively minor effect on the nucleate boiling heat transfer coefficient [16]. However, the CHF can be enhanced by higher flow rates, because, for a given spray nozzle, increasing the liquid flow rate is accompanied by an increased number of 
droplets, which causes more frequent bubble puncturing and increases the number of secondary nuclei, enhancing heat fluxes and CHF [21].

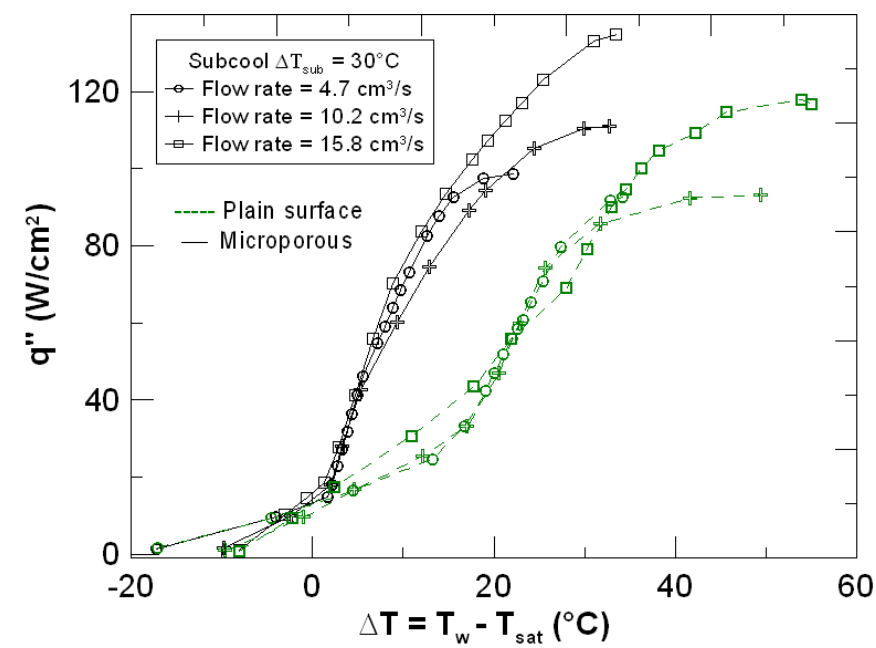

(a)

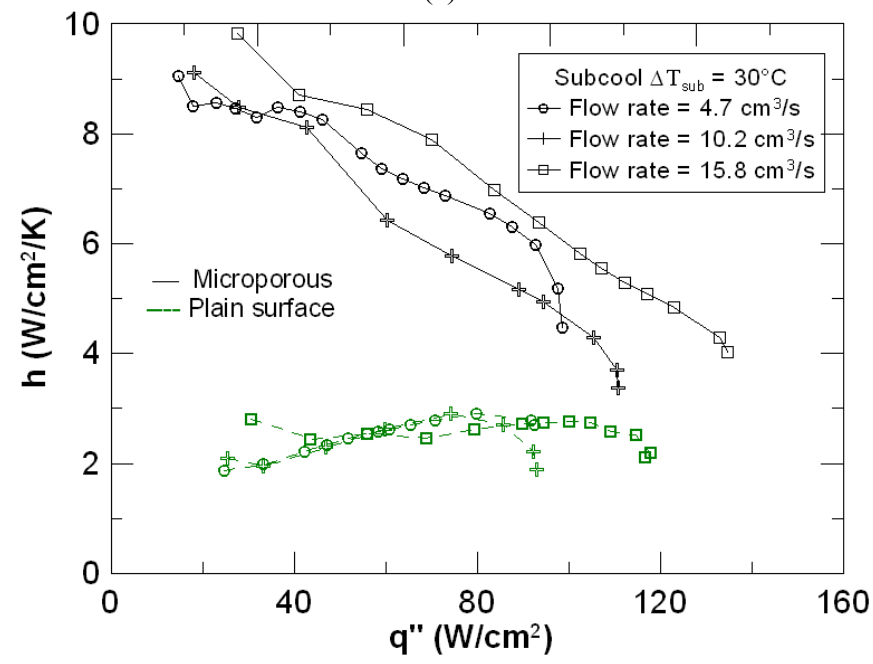

(b)

Figure 9 Effect of the spray flow rate, with subcooled spray: (a) boiling curves and (b) heat transfer coefficients.

For the subcooled spray (Fig. 9), the effect of flow rate on $h$ is quite small for both surfaces. However, in the case of the near-saturated spray (Fig. 10), the increasing flow rate leads to a concomitant increase in the boiling heat transfer, especially for the plain surface. While there is a clear trend of increasing heat transfer performance with increasing flow rate, from pool boiling to $15.8 \mathrm{~cm}^{3} / \mathrm{s}$ on the plain surface (Fig. 10), the same cannot be said about the microporous surface. At low heat fluxes on the microporous surface, the liquid spray seems to have little effect on the heat transfer performance, and even pool boiling performs as well as the spray. This is possibly because, on the microporous surface, phase change heat transfer is the dominant part of the heat transferred from the surface because of the large nucleation site density, and the convective heat transferred is smaller because of the higher resistance to fluid flow on the surface. In the case of the plain surface, because of the lower bubble density and smoother surface, the resistance to the liquid flow on the surface is considerably smaller, and the convective heat transferred forms a larger part of the total heat flux removed. Consequently, the flow rate has a considerably greater effect on the $h$ on the plain surface. The CHF, however, increases monotonically with the spray flow rate.

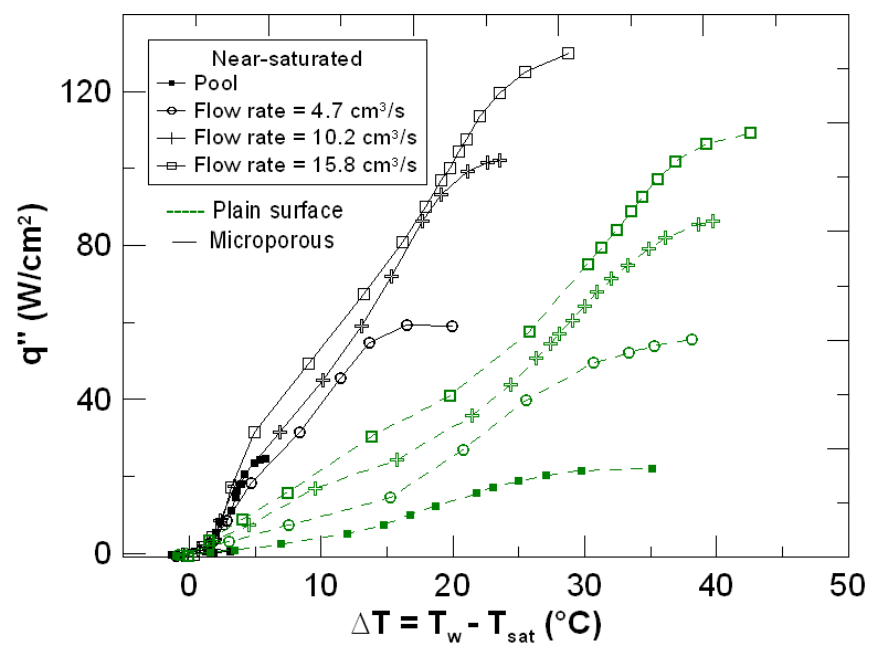

(a)

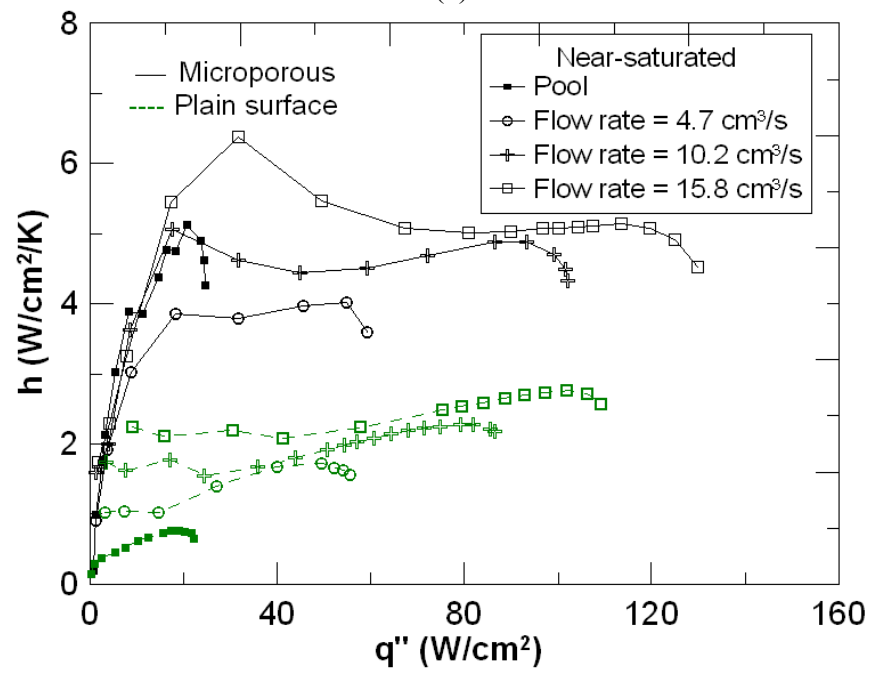

(b)

Figure 10 Effect of flow rate with the near-saturated spray: (a) boiling curves and (b) heat transfer coefficients. The pool boiling data are also shown for comparison.

\section{CONCLUSIONS}

Pool boiling and spray impingement boiling experiments were performed on copper surfaces coated with a thermally conductive copper microporous coating and copper nanowire coating, for comparisons to a plain surface. Promising heat transfer performances were obtained with the enhanced 
surfaces in comparison to the plain surface. Under all conditions tested, both enhanced surfaces showed lower incipience temperatures than those of the plain surface. In pool boiling with the surfaces oriented vertically in the pool, the microporous surface showed $\sim 500 \%$ increase in the heat transfer coefficient at the same heater power and $\sim 10 \%$ increase in the CHF in comparison to the plain surface. The nanowire surface showed approximately a $60 \%$ increase in the $h$ near the $\mathrm{CHF}$, while the CHF itself was considerably lower.

Spray tests were performed at flow rates of $4.7 \mathrm{~cm}^{3} / \mathrm{s}, 10.2$ $\mathrm{cm}^{3} / \mathrm{s}$, and $15.8 \mathrm{~cm}^{3} / \mathrm{s}$ on the microporous surface, with liquid subcooling of $30^{\circ} \mathrm{C}$ and $1^{\circ} \mathrm{C}$. Only the lowest flow rate was tested on the nanowire surface. The performance of the spray cooling at low flow rate on the nanowire surface, in comparison to the plain surface, was similar to that observed in the pool boiling experiment (enhanced $h$ and lower CHF with respect to the plain surface). However, the nanowire surface showed degradation in further tests. The short nanowire array used in the current study is not optimized for heat transfer. We expect that a further increase in the heat transfer, along with a higher CHF, may be obtained once the nanowire surface is optimized. The microporous surface showed a $100 \%-300 \%$ increase in the $h$ at all subcooling levels and flow rate levels over the plain surface. The CHF increased by $7 \%-20 \%$ for the microporous surface over the plain surface for identical conditions, depending on the flow rate. We observed that subcooling of the liquid had a strong positive effect at low flow rates throughout the nucleate boiling regime and at the lower heat fluxes in the sprays with higher flow rates. However, at the highest heat fluxes with high flow rate sprays, the subcooling had an insignificant effect. The effect of the flow rate on $h$ was found to be small for the subcooled spray, while in the saturated case, $h$ increased with increasing flow rate. The CHF increased with increasing flow rate irrespective of the level of liquid subcooling.

A full understanding of the mechanisms leading to the performance improvements observed here is necessary in order to further optimize the surface modifications. We are currently developing methods to obtain quantitative information regarding the relations between the surface structure and the flow field so as to develop a mechanistic model to explain the observations made here.

With suitable modifications of the processing conditions, some of these enhanced surfaces could potentially be employed in power electronics package cooling, thereby resulting in more efficient and greater heat dissipation from power electronics devices. This will help in achieving the broader goals of increased power density and more compact, lightweight power electronics modules.

\section{ACKNOWLEDGMENTS}

The authors would like to acknowledge the support provided by Susan Rogers, Technology Development Manager for Power Electronics and Electric Machines, Vehicle Technologies Program, DOE Office of Energy Efficiency and Renewable Energy. They are also grateful to Phillip Tuma (3M
Company) for providing the microporous coated surface, and to members of the Power Electronics team at NREL for fruitful interactions.

\section{NOMENCLATURE}

$$
\begin{aligned}
& \mathrm{CHF}=\text { critical heat flux, } \mathrm{W} / \mathrm{cm}^{2} \\
& h=\text { heat transfer coefficient }=q^{\prime \prime} /(\Delta T), \mathrm{W} / \mathrm{cm}^{2} / \mathrm{K} \\
& I=\text { current, A } \\
& q=\text { power, } \mathrm{W} \\
& q "=\text { heat flux, } \mathrm{W} / \mathrm{cm}^{2} \\
& T=\text { temperature, }{ }^{\circ} \mathrm{C} \\
& \Delta T=\text { surface superheat }=T_{w}-T_{\text {sat }},{ }^{\circ} \mathrm{C} \\
& V=\text { voltage, } \mathrm{V}
\end{aligned}
$$

\section{Subscripts}

$$
\begin{aligned}
& \text { calc }=\text { calculated from the two thermocouples } \\
& \text { in }=\text { input } \\
& \text { liq }=\text { liquid } \\
& \text { sat }=\text { saturation } \\
& \text { sub }=\text { subcooling } \\
& \mathrm{w}=\text { wall (surface) }
\end{aligned}
$$

\section{REFERENCES}

1 Bennion, K., 2007, Plug-in Hybrid Electric Vehicle Impacts on Power Electronics and Electric Machines, National Renewable Energy Laboratory report NREL/MP-540-36085, Golden, CO.

2 Honda, H., and Wei, J.J., 2004, "Enhanced Boiling Heat Transfer from Electronic Components by Use of Surface Microstructures," Experimental Thermal and Fluid Science, 28, 159.

3 Chang, J.Y., and You, S.M., 1997, "Boiling Heat Transfer Phenomena from Microporous and Porous Surfaces in Saturated FC-72," International Journal of Heat and Mass Transfer, 40, 4437.

4 Kim, J.H., Rainey, K.N., You, S.M., and Pak, J.Y., 2002, "Mechanism of Nucleate Boiling Heat Transfer Enhancement from Microporous Surfaces in Saturated FC-72," ASME Journal of Heat Transfer, 124, 500.

5 Ammerman, C.N., and You, S.M., 1998, "Consecutive-Photo Method to Measure Volume Flow Rate During Boiling From a Wire Immersed in Saturated Liquid," ASME Journal of Heat Transfer, 120, 561.

6 El-Genk, M.S., and Parker, J.S., 2005, "Enhanced Boiling of HFE-7100 Dielectric Liquid on Porous Graphite," Energy Conversion and Management, 46, 2455.

7 Liter. S.G., and Kaviany, M., 2001, "Pool Boiling CHF Enhancement by Modulated Porous Layer Coating: Theory and Experiment," International Journal of Heat and Mass Transfer, 44, 4287. 
8 Li, C., Wang, Z., Wang, P., Peles, Y., Koratkar, N., and Peterson, G.P., 2008, "Nanostructured Copper Interfaces for Enhanced Boiling," Small, 4, 1084.

9 Chen, R., Lu, M.C., Srinivasan, V., Wang, Z., Cho, H.H., and Majumdar, A., 2009, "Nanowires for Enhanced Boiling Heat Transfer," Nano Letters, 9, 548.

10 Estes, K.A., and Mudawar, I., 1995, "Comparison of TwoPhase Electronic Cooling Using Free Jets and Sprays," Journal of Electronic Packaging, 117, 323.

11Mudawar, I., 2001, "Assessment of High-Heat-Flux Thermal Management Schemes," IEEE Transactions in Components and Packaging Technologies, 24,122.

12 Kim, J., 2007, "Spray Cooling Heat Transfer: The State of the Art," International Journal of Heat and Fluid Flow, 28, 753.

13 Horacek, B., Kiger, K.T., and Kim, J., 2005, "Single Nozzle Spray Cooling Heat Transfer Mechanisms," International Journal of Heat and Mass Transfer, 48, 1425.

14 Kim, J.H., You, S. M., and Choi, S.U.S., 2004, "Evaporative Spray Cooling of Plain and Microporous Coated Surfaces," International Journal of Heat and Mass Transfer, 47, 3307.

15 Bostanci, H., Rini, D.P., Kizito, J.P., and Chow, L.C., 2009, "Spray Cooling With Ammonia on Microstructured Surfaces: Performance Enhancement and Hysteresis Effect," ASME Journal of Heat Transfer, 131, 071401.

16 Mudawar, I., and Estes, K.A., 1996, "Optimizing and Predicting CHF in Spray Cooling of a Square Surface," ASME Journal of Heat Transfer, 118, 672.

17 3M Product Brochure, 2008, 3M Microporous Metallic Boiling Enhancement Coating (BEC) L-20227.

18 Tuma, P.E., 2006, "Evaporator/Boiler Design for Thermosyphons Utilizing Segregated Hydrofluoroether Working Fluids," IEEE Semiconductor Thermal Measurement and Management Symposium, 69-77.

19 Chen, X., Duan, H., Zhou, Z., Liang, J., and Gnanaraj, J., 2008, "Fabrication of Free-Standing $\mathrm{Cu}$ Nanorod Arrays on $\mathrm{Cu}$ Disc by Template-Assisted Electrodeposition," Nanotechnology, 19, 365306.

20 Rainey, K.N., and You, S.M., 2001, "Effects of Heater Size and Orientation on Pool Boiling Heat Transfer From Microporous Coated Surfaces," International Journal of Heat and Mass Transfer, 44, 2589.

21 Rini, D. P., Chen, R.H., and Chow, L.C., 2002, "Bubble Behavior and Nucleate Boiling Heat Transfer in Saturated FC72 Spray Cooling," ASME Journal of Heat Transfer, 124, 63. 


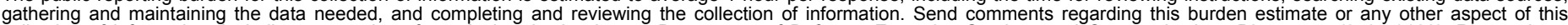

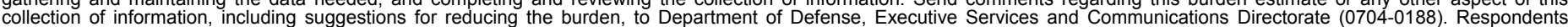

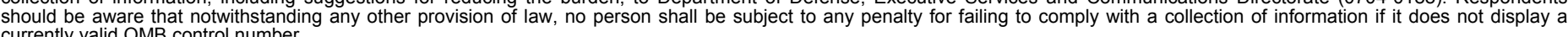

PLEASE DO NOT RETURN YOUR FORM TO THE ABOVE ORGANIZATION.

\section{REPORT DATE (DD-MM-YYYY) August 2010}

4. TITLE AND SUBTITLE

Enhancement of Heat Transfer with Pool and Spray Impingement Boiling on Microporous and Nanowire Surface Coatings
3. DATES COVERED (From - To)

5a. CONTRACT NUMBER

DE-AC36-08-GO28308

5b. GRANT NUMBER

5c. PROGRAM ELEMENT NUMBER

5d. PROJECT NUMBER

NREL/CP-540-48055

5e. TASK NUMBER

FC08.7000

5f. WORK UNIT NUMBER
7. PERFORMING ORGANIZATION NAME(S) AND ADDRESS(ES)

National Renewable Energy Laboratory

1617 Cole Blvd.

Golden, CO 80401-3393
8. PERFORMING ORGANIZATION REPORT NUMBER

NREL/CP-540-48055

9. SPONSORING/MONITORING AGENCY NAME(S) AND ADDRESS(ES) 10. SPONSOR/MONITOR'S ACRONYM(S)
NREL

11. SPONSORING/MONITORING AGENCY REPORT NUMBER

12. DISTRIBUTION AVAILABILITY STATEMENT

National Technical Information Service

U.S. Department of Commerce

5285 Port Royal Road

Springfield, VA 22161

13. SUPPLEMENTARY NOTES

14. ABSTRACT (Maximum 200 Words)

The DOE National Renewable Energy Laboratory (NREL) is leading a national effort to develop next-generation cooling technologies for hybrid vehicle electronics. The goal is to reduce the size, weight, and cost of power electronic modules that convert direct current from batteries to alternating current for the motor, and vice versa. Aggressive thermal management techniques help to increase power density and reduce weight and volume, while keeping chip temperatures within acceptable limits. The viability of aggressive cooling schemes such as spray and jet impingement in conjunction with enhanced surfaces is being explored. Here, we present results from a series of experiments with pool and spray boiling on enhanced surfaces, such as a microporous layer of copper and copper nanowires, using HFE-7100 as the working fluid. Spray impingement on the microporous coated surface showed an enhancement of $100 \%-300 \%$ in the heat transfer coefficient at a given wall superheat with respect to spray impingement on a plain surface under similar operating conditions. Critical heat flux also increased by $7 \%-20 \%$, depending on flow rates.

\section{SUBJECT TERMS}

vehicle power electronics; power electronics thermal management; spray cooling; jet impingement cooling; immersion boiling; pool boiling

\begin{tabular}{|c|c|c|c|c|}
\hline \multicolumn{3}{|c|}{ 16. SECURITY CLASSIFICATION OF: } & \multirow{2}{*}{$\begin{array}{l}\text { 17. LIMITATION } \\
\text { OF ABSTRACT } \\
\text { UL }\end{array}$} & \multirow{2}{*}{$\begin{array}{l}\text { 18. NUMBER } \\
\text { OF PAGES }\end{array}$} \\
\hline $\begin{array}{l}\text { a. REPORT } \\
\text { Unclassified }\end{array}$ & $\begin{array}{l}\text { b. ABSTRACT } \\
\text { Unclassified }\end{array}$ & $\begin{array}{l}\text { c. THIS PAGE } \\
\text { Unclassified }\end{array}$ & & \\
\hline
\end{tabular}

19a. NAME OF RESPONSIBLE PERSON

19b. TELEPHONE NUMBER (Include area code) 